\title{
Perceptions of Clinical Leadership in an Aged Care Residential Facility in Perth, Western Australia
}

\author{
David Stanley $^{1 *}$, Karen Latimer ${ }^{2}$ and Julie Atkinson ${ }^{3}$ \\ ${ }^{1}$ University of Western Australia, Australia \\ ${ }^{2}$ Senior Lecturer, Curtin University, Australia \\ ${ }^{3}$ Swan Care Group, Bentley Park, Perth, Australia
}

\begin{abstract}
Objective: To investigate the perceptions and approaches to leadership and leadership development of senior nurses and care home managers in an aged care residential facility.

Method: A descriptive phenomenological research approach was employed to support purposive sampling. A questionnaire $(n=10)$ was used, followed by interviews $(n=8)$. Analysis employed an SPSS and NVivo 0.6 computer programs, with manual data configuration as required.

Results: Participants saw a distinction between their role as leaders and managers and that their more clinically focused responsibilities favoured a greater affinity with clinical leadership. In addition, the attributes and characteristics of clinical leaders identified by participants were approachability, clinical skills, clinical knowledge, honesty, integrity, support for others and visibility in the clinical area.

Conclusion: The development and deployment of clinical leadership attributes are vital so that senior nurses and care home managers can play a more effective part in care provision and service improvement in the residential care environment.
\end{abstract}

Keywords: Clinical leadership; Aged care; Residential care leadership, Phenomenological research

\section{Introduction}

In Australia people are living longer and are also well supported with an excellent health system and social welfare structures [1]. Nevertheless, in Australia $80 \%$ of people over the age of 65 have three or more chronic conditions and older people with chronic illnesses are the highest users of all health and aged care services [2]. The aged care sector, while facing increasing care and quality demands is also feeling; the impact of a reducing qualified nursing staff pool; a transient and mobile management and nursing workforce; the perception that their service is of lower status compared with acute and community nursing services; and the view, in some quarters, that resources in the field are poor. These perspectives are compounded by the view that most of the care is offered by unskilled workers who, along with the qualified workforce, are poorly paid [3-8]

In May 2010, the Australian Government announced that it would promote change in practice and build clinical leadership capacity [9]. Despite this high level initiative, limited research exists that explores and describes what clinical level leadership is, who the clinical leaders are and the characteristics and attributes of clinical leaders in aged care residential facilities [10-13].

With the challenges and opportunities that abound in the residential aged care sector, management skills and leadership approaches are considered vital for addressing and dealing effectively with developments in care provision and service improvement in the care home environment. However, while much is known about the impact of management and leadership in the corporate or industry sectors, little is known about how leadership is perceived or how leadership can facilitate effective change and impact positively on residential care, quality and staff attitudes.

\section{Key Points}

- Used data from questionnaires and interviews with senior nursing staff and care home managers at a residential care facility.

- The study investigated the perceptions of clinical leadership and approaches to leadership development.

- Participants described the characteristics or attributes they saw as vital for a clinical leader.

- Data was offered about how leadership skills were obtained and insights into the difference between leadership and management.

- Participants also identified the issues that may hinder or stifle clinical leadership development in the aged care environment and recommendations and suggestions were made that have implications for nursing practice.

\section{Background and Literature Review}

The research was undertaken because leadership is clearly recognised as a key factor in many areas of the health service [12,1416]. As well, given the perceptions alluded to above investigating the practice of leadership and how leadership can be fostered in the aged

*Corresponding author: Dr. David Stanley, School of Population Health, University of Western Australia, 35 Stirling Road, Crawley, WA 6009, Australia, Tel: 0428894571 E-mail: david.stanley@uwa.edu.au

Received February 11, 2014; Accepted March 05, 2014; Published March 07, 2014

Citation: Stanley D, Latimer K, Atkinson J (2014) Perceptions of Clinical Leadership in an Aged Care Residential Facility in Perth, Western Australia. Health Care Current Reviews 2: 122. doi: 10.4172/2375-4273.1000122

Copyright: $\odot 2014$ Stanley D et al. This is an open-access article distributed unde the terms of the Creative Commons Attribution License, which permits unrestricted use, distribution, and reproduction in any medium, provided the original author and source are credited. 
care sector is vital for effectively establishing leadership's influence on quality care and improvements in the life of residents and staff in the residential care field. There are few empirically based, leadership focused studies identified in the literature and this study would set the scene for a fertile area of research that the Department of Health and Aging $[15,16]$ recognise as key in developing quality and establishing accountability in the aged care arena.

\section{Leadership and nursing}

There is a wealth of literature that deals with the role, nature and purpose of nursing leadership, the value of developing and nurturing nurse leaders and the characteristics of nurse leaders. Publications about nursing leadership abound and address the nature and purpose of leadership and leadership styles [12,13,17-19]. Much of the literature reviewed uses the terms 'leadership' and 'management' interchangeably with little attempt to define either term [10-12,20-22] and as a result, much of it fails to clarify who the leaders are, other than deference to their hierarchical position [23]. The pool of information related to 'management' in the aged care arena is substantial, although literature related to 'leadership' in the aged care arena is shallow and would benefit from research to generate information and knowledge about the application and perception of leadership.

There are a number of reasons offered that support and justify this research:

1. The ability to generate leadership is clearly becoming recognised as a key factor in many areas of the health service [12,1416]. Investigating the practice of leadership and how leadership can be fostered in the aged care sector is vital for effectively establishing leadership's influence on quality care and improvements in the life of residents and staff in the aged care area.

2. There are few empirically based, leadership focused studies identified in the literature and this study would set the scene for a fertile area of research that the Department of Health and Aging $[15,16]$ recognise as a key area in developing quality and establishing accountability in the aged care arena.

3. The pilot study offered a minor collaboration opportunity that facilitated a link between UWA and Swan Care Group. This may be useful in terms of support for future student clinical placements, training support for Swan Care Group staff and further research ventures.

4. In 2010 a similar study was undertaken with the St. John's Ambulance service in Western Australia [13] Linking the results from this and previous research that offer interesting insights into the profile of clinical leaders in these diverse clinical fields [24].

\subsection{Nursing leadership in the aged care environment}

While many publications outline the role of effective management to address care and quality issues in the aged care sector, fewer publications were identified that outline the relevance of leadership in the aged care sector, although more and more appear to be evident as the significance of leadership issues are raised. In 2008, the Office of Aged Care Quality and Compliance released a report on residential care and suggested that aged care residential providers take a proactive role in promoting leadership in their facilities [15]. This was reinforced at the 'Better Practice in Aged Care' conference supported by the Aged Care Standards and Accreditation Agency, when it was suggested that visionary leadership was required to improve the lives of care home residents [16].
Other publications have linked developments in aged care leadership with improving the care and management of elderly resident's chronic pain [25] and with improvements in team work and communication [26]. Two Australian papers link leadership development with innovative practice in the aged care sector $[27,28]$ and Jeon, Merlyn and Chenoweth offer the most extensive literature review of leadership and management in the aged care sector with a 'narrative synthesis' that finally identified 153 publications relevant to the topic of leadership and management and aged care [29]. This study concluded that the literature provided 'ample' evidence of the impact of management and leadership on matters of staff turnover, retention, leave and absenteeism. As well, the literature dealt in detail with management issues such as staff performance, staff organisational commitment, job satisfaction, productivity and care quality. However, they noted that little evidence of experimental studies existed and few studies dealt with 'leadership.' Indeed they concluded that while 'most' studies were conducted in the UK and North America, "no Australian study was found that describes a particular leadership program or model specifically designed for the residential aged care setting, thereby paving the way for a well-designed effective study in the future" [29].

\section{Method}

\section{Aim}

To explore the perceptions of leadership and approaches to leadership development of senior nurses and care home managers in one aged care residential facility in Perth, Western Australia.

\section{Design}

The methodological principles of the research rest upon descriptive phenomenology, a methodological approach that can be used to describe the everyday world of human experience [30]. This approach supports the use of purposive sampling for recruitment and allowed the researcher to "bracket" concepts, thus helping the researcher to reflect upon their own personal assumptions, biases, beliefs and attitudes about the phenomenon [30]. This study produced both qualitative (interviews) and quantitative (questionnaires) data.

\section{Data collection}

The principle methods employed to generate data in this study were a questionnaire and an interview. Questions for both methods were developed from the literature review, consultation with colleagues and past experience in the application of nursing leadership approaches in practice, all based on a similar UK study and study with the St. John Ambulance Service in Western Australia. The advantage of using interviews was that it allowed all the participants to offer their views and respond in a considered way to the questions asked. Although this approach is more expensive and more time consuming than other sampling methods, an interview, used in conjunction with the questionnaire allowed considerable depth of data to be secured and ensure a more personal approach to securing respondent participation. As well these methods facilitated an appropriate phenomenological approach to the study.

\section{Ethical considerations}

Ethical issues were in keeping with the National Health and Medical Research Council, Australian Code for the Responsible Conduct of Research (2007) [31]. Ethical approval was sought and secured through a university research ethics approval process and followed permission from the health agency. Confidentially for all 
participants were respected and at no point did the researcher record the participant's names or personal details. Each questionnaire was provided with an accompanying explanation letter outlining the research aims and addressing issues of confidentiality, ethical approval and the participant's right to withdraw with impunity (by simply not returning the questionnaire). Each interview participant was offered the same set of questions to consider was provided with a consent form and an accompanying explanation letter outlining the research aims and addressing issues of confidentiality, ethical approval and the participant's right to withdraw, again with impunity. No participant information in either the questionnaires or interviews was linked to individual respondents and participant anonymity has been assured. As well, it was made clear that the research was not related to the participant's employment or work performance and any information of a confidential or sensitive nature was to be and has been kept secret and secure. All data remains securely locked in a file at the University of Western Australia where the primary researcher now works. Returned questionnaires will be destroyed after 5 years.

\section{Data analysis}

Interview data was analysed with the aid of an NVivo 0.6 computer program and with manual data configuration as required [32]. Questionnaire data was analysed with the aid of an SPSS computer program for quantitative data. This was achieved by following steps outlined by Smith, Flowers \& Larkin [33]. These steps include; reading and re-reading, initial noting, developing emergent themes, searching for connections across emergent themes and examining levels of interpretation. The data collected from the interviews require the information to be broken down, examined, compared, conceptualised and categorised [34]. Each of these approaches focuses on different interpretations of the data as they are distinctive analytical processes [33-35].

\section{Participants}

Purposive sampling was used for selecting the participants from the senior nursing staff or care home managers of a large residential facility. There were 19 participant details provided at the beginning of the research study period (March 2012 to June 2012). Of these one left during the research period and two new participants were identified, bringing the final total to 20 senior nursing staff or care home managers (roles and responsibilities were commonly interchangeable and sometimes depended on the shift pattern). Of the 20 potential study participants, ten returned questionnaires (50\%) and eight participants were interviewed (40\%). Four participants completed the questionnaires and were also interviewed.

\section{Limitations}

This research was only offered as a pilot study and as such focused on only one residential facility. The funding for the study was limited, suggesting that while an adequate number of participants were recruited at the Swan Care Group facility in Bentley, a larger and wider study was not possible. Therefore, the limited sample size in the questionnaires could be seen as a limitation. As well, four of the senior nursing or care home manger staff at Swan Care Group, Bentley at the time of the study were male, no male staff returned questionnaires and only one male volunteered to be included in the interview group. As such, the views expressed are dominantly those of the female senior nursing and care home staff at the facility.

\section{Findings}

As two data methods were used (a questionnaire and interviews) the results from both of these methods are offered separately.

\section{Findings - The Questionnaire}

The questionnaire respondents average length of service with Swan Care, Bentley was just under 9 years (8.63 years) with the longest service of any respondent being 40 years (question 14). However, 4 of the respondents had worked at Swan Care for less than 12 months. The gender make-up of the respondents to the questionnaire showed that no male staff responded. This is not in keeping with the profile of men in nursing and indeed four of the senior nursing staff working at Swan Care, Bentley at the time of the study where men. They simply failed to respond to the questionnaire. The distribution of the ages of respondents shows that no respondent was below the age of 41 , with $30 \%$ being between $41-50,50 \%$ being between the age of $51-60$ and $20 \%$ of respondents being over the age of 60 .

This indicates that staff who responded to the questionnaire where all over the age of 41 and most were over 51, with one staff member indicating that they were 74 years of age.

No respondent indicated that they had any formal leadership training and only one respondent indicated that they had received some sort of management training.

How do you know a clinical leader? Respondents were offered a list of 54 attributes or descriptive words taken from a wide range of literature describing leaders (Table 1).

Participants were asked to indicate with a "tick" those characteristics/ attributes they saw as "most" identifiable with clinical leaders. Table two lists the top 10 characteristics indicated by respondents (Table 2).

Other terms that may have been expected to be associated with leadership roles such as vision and creativity (both associated with transformational leadership) were selected much less commonly $(40 \%)$ and $(50 \%)$ respectively. Respondents were offered the same list of attributes (Table 1) and asked to indicate with a "cross" those characteristics/attributes they saw as "least" identifiable with clinical leaders (Table 3).

Other Qualities: Respondents were asked to suggest other qualities or characteristics of a clinical leader not on the list of 54 attributes. Few additional words were suggested although Trustworthy, Responsible, None-judgemental, Reliable, Enthusiastic, Experienced and Friendly were offered.

Their role: Half (50\%) explained that they saw themselves as clinical leaders, because they thought they were, "experienced in their role" or identified their role with the facilitation of change. Few respondents $(30 \%)$ thought their role called for them to engage in management. These $30 \%$ stated that they managed "the day-to-day operation," "worked in a complex environment," or "dealt with processes rather than people." The majority of respondents (70\%) indicated that they did not see themselves as managers, stating that they, "preferred working directly with residents and their families" or simply that they "preferred to work with people." Implying that they saw managers as less, client / people focused.

Leadership capacity: All the respondents (100\%) suggested that they were facilitated to lead and collaborate in clinical practice, with comments such as; "I am placed in a situation where I have to be a leader," "part of my role is to work collaboratively" and "I am required to 
provide clinical leadership across a number of facilities therefore I must lead and work collaboratively." However, few thought their colleagues saw them as clinical leaders, while most $(60 \%)$ thought they were seen as both a leader and manager. When asked to offer a reason for their response, most indicated that they "were often the only member of staff that others could come to with issues," or that they "managed the operation on a daily basis." Of the few that thought their colleagues did see them as a clinical leader, most suggest it was because they had, "relevant clinical experience", "had their colleagues' respect" or because "they were approachable and knowledgeable."

The difference between leadership and management: Half (50\%) offered their views on the difference between leadership and management, indicating that leadership was; "being able to work alongside your colleagues," or about "leading by example" and was, "more directly involved with the 'floor level."

Management was described as being in an "overseer role," relating to "processes," "offering direction or orders," "being removed from the day-today resident care" and "involved more corporate issues."

Barriers: Most (60\%) indicated "yes," some (30\%) indicating "no," but added no reason why and 1 person (10\%) suggested they were "not sure" about barriers. When asked for the reasons for the barriers a number of responses were offered. These are included in Table 4.

\section{Findings - The interviews}

Interviews were conducted with eight participants (40\% of the potential interviewees). Interviews were conducted on site, in a ward office or dining area and at a time that was convenient to the staff member. Each potential interviewee was approached either opportunistically, when the interviewer was on site or at a pre-arranged time following a phone call to make an appointment. No one was coerced into an interview and consent was sought in each case. Each interview undertaken was conducted within 60 minutes in order to limit the disruption to the participant's duties and responsibilities and four of those interviewed had also completed the questionnaire.

Questions focused on a number of areas identified as significant following an analysis of the questionnaire data and as a result of a predetermined field of enquiry about clinical leadership. Detailed demographic data was not recorded to aid in participant anonymity.
The interviews were recorded and transcribed verbatim then subjected to a thematic analysis using an Nvivo 6.0 computer program [32]. This involved detailed analysis, reading and re-reading each interview and identifying categories, sub-themes and themes within the data that outlined and explained the interviewee's understanding of clinical leadership and other related issues. Six themes were identified from the data analysed (Tables 5 and 6).

Theme 1: The clinical leader's role: This theme grew from the sub-themes "clinical skills", "dealing with others" and "supervising and coordinating care at the bedside". These themes developed as respondents discussed their role at Swan Care Group, Bentley. In describing their role respondents suggested:

"I care for residents directly by providing medications and doing dressings and I have a hands on role in coordinating the activities of other carer staff and working as a link person with other disciplines or professionals."

Management activities were not mentioned and in general each respondent saw themselves as central to the delivery of clinical care and the coordination of care in general.

Theme 2: The difference between a manager and a leader: Categories identified to support this theme were sub-divided into "Leadership attributes" and "Manager attributes" with respondents identifying a range of attributes often in-keeping with the descriptive words identified in the questionnaire data that outlined their views of the key attributes for a leader or a manger within the aged care environment. Respondents suggested that:

"I think there is quite a lot of difference between a manager and a leader... a manager is more like...you know...saving money while leaders really look for quality."

Leaders were described as dealing with the quality of care and how care can be improved, with the bigger picture, people, and teams and with "hands on", floor work. Managers were described as "having authority and dealing with the day-to-day stuff" and "taking responsibility for the residents". Leaders were seen to be recognised as functioning at "any level". Managers though were described as being responsible for "ordering people to do things", while not always being seen to listen to staff. Mangers were described as "thinking differently

\begin{tabular}{|c|c|c|}
\hline Copes well with change & Is a motivator & Deals with routine \\
\hline Sets direction (planning) & Is controlling & Is consistent \\
\hline Considers relationships valuable & Has management experience & Copes well with Complexity \\
\hline Flexible & Is a teacher & Is visible in practice \\
\hline A guide & Is a mentor & Is a visionary \\
\hline Sets goals and targets & Is a negotiator & Directs and helps people \\
\hline Has integrity and is honest & Is responsible for others duty/responsibilities & Deals with reward/punishment \\
\hline Is inspirational & Takes calculated risks & Aligns people \\
\hline Is a critical thinker & Is a regulator & Counts on trust \\
\hline Is creative/innovative & Is analytical & Deals with resources allocation \\
\hline Is clinically competent & Is an administrator & Maintenance of relationships \\
\hline Is artistic/imaginative & Is conservative & Inspires confidence \\
\hline Is supportive & Is an advocate & Is articulate \\
\hline Is a change agent & Is approachable & Is just/fair \\
\hline Can be a decision maker & Is a coach & Manages staff \\
\hline Has a healthy sense of humour & Is caring/compassionate & Is an effective communicator \\
\hline Evaluates the performance of staff & Is a role model for others in practice & Resolves conflict \\
\hline Works alone & Must have relevant postgraduate training & Is courageous \\
\hline
\end{tabular}

Table 1: The 54 Characteristics/Attributes offered. 


\begin{tabular}{|l|l|l|}
\hline 1 & $100 \%$ & Is clinically competent/is approachable \\
\hline 2 & $100 \%$ & Is approachable \\
\hline 3 & $100 \%$ & Is supportive \\
\hline 4 & $100 \%$ & Has integrity and is honest \\
\hline 5 & $100 \%$ & Is an effective communicator \\
\hline 6 & $100 \%$ & Copes well with change \\
\hline 7 & $100 \%$ & Considers relationships valuable \\
\hline 8 & $100 \%$ & Inspires confidence \\
\hline 9 & $100 \%$ & Is visible in practice \\
\hline 10 & $90 \%$ & Is just and fair \\
\hline
\end{tabular}

Table 2: Qualities I characteristics "most" identified with clinical leaders.

\begin{tabular}{|l|l|l|}
\hline 1 & $80 \%$ & Is controlling \\
\hline 2 & $50 \%$ & Is artistic I imaginative \\
\hline 3 & $40 \%$ & Works alone (should be part of a team?) \\
\hline 4 & $30 \%$ & Is an administrator \\
\hline 5 & $30 \%$ & Must have a relevant post graduate degree \\
\hline 6 & $30 \%$ & Deals with reward and punishment \\
\hline 7 & $20 \%$ & Is conservative \\
\hline 8 & $20 \%$ & Deal with routine \\
\hline 9 & $20 \%$ & Takes calculated risks \\
\hline 10 & $10 \%$ & Manages staff \\
\hline
\end{tabular}

Table 3: Qualities I characteristics "least” identified with clinical leaders.

Workload - taking on all sorts of other responsibilities

Filling in for others and putting your own work quality at risk

Resistance from colleagues to change

Many staff being unable to understand English

Many staff being unable to speak effective English

Old ways of doing things

A lack of experience

Confusion about leadership and management

Few other experienced colleagues to act as role models

An aging work force

Table 4: Barriers impacting on the implementation of leadership.

from floor staff" and were seen to focus more on administration and communication with people outside the organisation.

Theme 3: Leadership Characteristics: Many characteristics were used to describe clinical leaders. These fell into a number of sub-themes that supported many of the attributes identified in the questionnaire aspects of the study. These themes suggested that clinical leaders needed;

"...communication skills, clinical skills and clinical knowledge and that you have to be visible in the ward area."

"Clinical leaders should act as a role model to others in the clinical area and work as part of the team and to be fair in their approach to others."

It was also suggested that clinical leaders could be identified at any level of the clinical team. In keeping with the questionnaire data "approachability" was identified as the most important characteristics of a clinical leader, while sound clinical and communication skills were seen as central to the ability of a clinical leader to function and be recognised as a clinical leader.

Theme 4: Preparation for the role: In response to questions about their preparedness for their role it is not surprising that respondents suggested they either felt "well prepared", "not well prepared" or that "they could do with on-going education" to keep up-to-date. Most comments suggested that the respondents felt well prepared, by having previous experience, seminars and adequate university preparation, although a number of respondents sought further education or had had no formal preparation for their leadership role or any management functions they may have been required to undertake.

Theme 5: Getting involved: This theme resulted from questions about how they, as clinical leaders managed to encourage initiative and participation or involvement from their colleagues. In effect the respondents described how they could; “....support my colleagues to get involved in care or care focused initiatives by using clear communication."

Clear communication included the issuing of orders as well as making clear what was expected of others, while some respondents recognised the value in "being positive toward others" and "getting to know people (as individuals) and not treating people like machines." This lead to motivating and inspiring clinical staff by recognising the importance "of connecting with colleagues as individuals."

Theme 6: Barriers to leadership potential: This theme resulted from direct questions about the barriers that clinical leaders faced in the aged care environment. A number indicated that they faced "no" barriers, but these views were rare. Most felt there were a number of barriers or "potential barriers." Offered were sub-themes such as communication issues with poor English language skills dominant among them. As well as being difficult for some staff it was identified that some residents struggled with their capacity to understand some staff's English expression or accent. This was an interesting observation during the data collection as on a number of occasions the researchers were unable to make them understood or gather quality data because of the respondent's poor English language comprehension. "Low staff numbers" or "poorly qualified staff members" were identified by a number of respondents as barriers to the development of their leadership potential, as was limited access to learning support and a lack of clarity around staff roles. Some respondents felt that staff numbers were not as much of an issues as much as access to (or support from) staff with higher qualifications who they could "bounce ideas off" or share ideas for further development. Also identified was a lack of time to carry out certain roles. Some staff also acknowledged that the barriers to their leadership development were "personal and reflected their own limited motivation to engage with on-going professional development."

\section{Discussion}

The discussion is a considered reflection of the results from the questionnaires, interviews, researcher's observations and literature informing an understanding of leadership within the Swan Care Group, Bentley facility.

With a return rate from the questionnaire of $50 \%$ and the interview rate of $40 \%$ it can be assumed that a considerable number of the senior nursing and care home management staff at Swan Care Group, Bentley expressed opinions and views about the topic of clinical leadership. As only four participants undertook both the questionnaire and interview it can be stated that the research has covered a substantial number of the senior nursing and care home management staff and as such offers valid and detailed research data.

Between March and June 2012 there was a potential of 20 senior nurses or care home managers that could have taken part in both aspects of the study. Demographic data was not collected during the interviews to aid in participant anonymity. The questionnaire data suggested that the average senior nurse or care home manager had 
Citation: Stanley D, Latimer K, Atkinson J (2014) Perceptions of Clinical Leadership in an Aged Care Residential Facility in Perth, Western Australia Health Care Current Reviews 2: 122. doi: 10.4172/2375-4273.1000122

Page 6 of 8

\section{Categories (Built from verbatim comments of participants)}

RN on the ward I Clinical skills/Medications I Care planning I Caring for clients I residents I "Hands on stuff" I Dressings I Making clinical decisions I Pain management

Delegation I Pharmacy liaison/Dealing with relatives I Working with other disciplines/Resident orientation to the home

Handover role I Day-to-day running of the ward I Supervising other clinical I care staff I I Coordinating care

Leaders deal with quality of care/leaders looks at how care can be improved/leaders have followers/leaders look at the bigger picture/ leaders deal with people/leaders deal with teams/leaders have a vision/leaders have authority/leaders involved with the day-to-day stuff/leaders are on the floor, "hands on"/leaders are responsible for the residents/leaders compromise more than managers/leaders are about teamwork/leaders can be at any level.

Managers order you to do things//Managers are about saving the money/Mangers think differently/managers tell and may not always listen/Managers do admin and communication with outside/ managers are the "bad guy" need a qualification to be a manager/ deal with you when you have done something wrong/managers are in an office.

Teach carers/supervise others/friendly/good communicator/deals with conflict/communicates effectively/open to new ideas/assertive/approachable/effective communication at handover/understand that it is OK to ask if you don't know something.

Provides direct care/knowledgeable/Clinical experience/A caring person/be seen doing things in a positive way/don't panic/be punctual/well organised/be flexible/must have sound clinical knowledge/responsible for updating their knowledge/good at delegation/ good clinical skills/manages their time well/great clinical skills

Be found on the "shop floor" with residents and carers/visible/build trust so people will come to you/be visible

Role model quality care/use EBP/not biased/does what they say they will do/acts on complaints/role model/building competence in those around you/leading by example

Leaders can be at any level

Teach others/works with a team/leads a team/helps build cooperation/

Honesty/Listens to others/approachable - most important/reliable/ fair/consistent/friendly

Feel I need more preparation/nothing formal offered/just thrown in/ Wanted needed to learn more

Previous aged care work experience/university course/previous nursing experience/seminars on aged care/learnt on the job/ hospital training helped/diploma from the UK

Refresher courses/just keep updated

Clear communication of what is required/just tell them to do things and they do it

I am respected because of my experience/people recognise my experience

Treat people (carers) like humans and not machines/offer support and getting support from above/being positive towards people/ getting to know people

Language skills/poor English language skills/my accent/many staff with English as a second language=hard at times for the residents at times/often need to use slow talk or pictures to communicate with some staff

Small number of registered nurses/not enough staff with registered nurse qualifications/Need more qualified staff/low staffing levels

Need more knowledge/more training to do this job/recognised

Danger of being so dependant of careers/clearer boundaries about the role/not knowing the "tricks" of older staff/still have to

follow up with some people to make sure they do things/carry a lot Role boundary or clarity issues of responsibility/sometimes have to supervise two clinical areas at

once/lack of other qualified staff to bounce ideas off

Feel I get a lot of support/management are wonderfu

Limited time to do everything/Lots of demands on my time/busy

job sometimes

Self-imposed limitations

\section{Sub-Themes}

Clinical skills

Dealing with others (relatives I staff I other professionals)

Supervising I coordinating care at the bedside

Leader attributes

The difference between a manager and a leader

Major Theme 1

Clinical Leader's role
Communications skills

Clinical skills and clinical knowledge

Visible

Leadership characteristics

\section{At any level}

Team Worke

Fair approach to others

Not well prepared

Well prepared

Preparation for the role

On-going education

Clear communication

Getting involved

Experience

Treat people well and with respect

Communication issues

Staffing issues

Learning issues

Barriers to leadership potential

Table 5: Categories I Sub-themes and Themes. 


\begin{tabular}{|l|l|}
\hline 1 & The clinical leader's role \\
\hline 2 & The difference between a manager and leader \\
\hline 3 & Leadership characteristics \\
\hline 5 & Preparation for the role \\
\hline 6 & Getting involved \\
\hline
\end{tabular}

Table 6: Summary of the main themes derived from the interviews.

worked at Swan Care Group, Bentley for just less than 9 years with one respondent having worked at the facility for 40 years, while 4 of the 10 questionnaire respondents had worked at Swan Care Group, Bentley for less than 12 months. Significantly, the participants who responded to the questionnaire where all over the age of 41 with most being over the age of 51 with all eight of the staff interviewed sitting within the 4151 age bracket. Unlike the questionnaire data the interviews included the views of one male, with the remaining interviewees being female.

The results of this study indicated that the attributes and characteristics of clinical leaders identified by the participants in the study are consistent with results from other, similar studies from other health care fields $[11,13,24]$. Approachability, good clinical skills, clinical knowledge, honesty, integrity, support for others and visibility in the clinical area being dominant attributes of the clinical leaders. It was also noted that participants saw a distinction between leadership and management and that their more clinically focused roles lead them toward a greater focus on leadership. However, few had any leadership instruction and almost all saw barriers that hindered the development or application of leadership in the care home environment (Table 4).

$\backslash$ Few of the participants saw themselves as managers, although a few indicated that they sometimes undertook management functions. This was consistent with the research results of Cook [36] who suggested that clinical leaders were likely to come from across the spectrum of staff but more likely to be from staff with a clinical, rather than management focus. The majority of those interviewed said that they preferred to work directly with residents in a clinical capacity and that this was incompatible with a manager's role, adding that they saw themselves as being clinically skilled and clinically focused or coordinating care through others. Only a few of the respondents to the questionnaire thought their colleagues saw them as clinical leaders. In the original nursing research $[10,11]$ and later research with ambulance staff $[13,24]$ the majority of those nominated as clinical leaders by their colleagues failed to recognise themselves as such. Therefore, while clinical leaders are evident in clinical practice in significant numbers [11] many fail to recognise either themselves or their colleagues as leaders if they do not hold a management position or title.

Most of the interview participants failed to mention "management" as a significant aspect of their role and all felt themselves drawn to the delivery of clinical care and the coordination of care by others as the key attributes of their role. The net result was that while few participants saw themselves as managers (even if others may have), most failed to recognise themselves as clinical leaders either, leaving them to occupy a sort of limbo position between leadership and management and having, as a result, limited authority or power to effectively lead if needed or manage if desired. Many participants failed to recognise themselves as clinical leaders and some seemed to suffer from a degree of role ambiguity as a result [32].

It was significant that none of the respondents to the questionnaire or interviews discussed any formal leadership or management instruction or education and most if they had gathered information on the topic of leadership, had done so simply by picking it up along their career journey.

All of the interviewees indicated that they saw their role as relating to that of a clinical leader and not a manager. Most of the questionnaire and interview data suggested that participants did not see themselves as managers because they saw managers dealing with authority and finances, and themselves dealing more with people, other staff, and the coordination of care or the delivery of direct resident care. Less clinically focused staff (managers) where not regarded as fitting the description of a clinical leader and they were classified clearly as having more management responsibilities. These findings are consistent with other research results $[11,13,24,36,37]$ and confirmed the view that clinical leaders could be found at any level of the organisation as long as their role involved a substantial clinical focus and attention to direct resident care or the coordination of those who delivered direct resident care. Participants involved in this study could be described as clinical leaders, even though a few saw themselves as managers and most had a limited insight into their limbo clinical role or pseudo-management responsibilities.

Most of the respondent's highlighted barriers that stopped them implementing leadership (Table 4). Few of these problems seem insurmountable, however for them to be overcome, barriers need to be recognised and addressed openly and with considerable consultation. A key feature of the study was to identify the qualities and characteristics of clinical leaders in the aged care setting. As such, respondents and interviewees were offered an opportunity to rate and describe the characteristics they associated "most" or "least" with clinical leaders. The results were consistent with the results from other studies related to clinical leadership attributes $[10,11,13,24,37]$ and are outlined in Table 1 . The interviews re-enforced these attributes describing clinical leaders as having good communication skills, sound clinical skills and clinical knowledge, being visible in practice, acting as role models, being fair and approachable and working within and as part of a team. Approachability was sighted as the most important characteristic and in the questionnaires and again in-keeping with the two previous studies $[10,11,13]$ being seen as "controlling" was considered the least favourable clinical leader attribute. Most interviewees while prepared for their clinical role were commonly unprepared for their leadership responsibilities (or indeed management tasks if these were required).

Clinical leaders are (in part) recognised because they support and motivate others, although few participants saw themselves as clinical leaders or genuinely understood their role as clinical leaders. Most felt clear communication, the possession of sound clinical experience and the ability to treat people with respect or be positive toward people were all that were needed to motivate and support others to get involved in making care better. While these approaches are essential, little more than these approaches was discussed and as such the potential for greater innovation or capacity to improve care seemed minimal. If clinical leaders are to genuinely impact on the quality of care and make care better they need to have a clear understanding of how to motivate others and build their team's capacity. The researcher's noted that while often understated by the participants in the study, the barriers discussed seemed more in evidence than was acknowledged offering a possible reason for the limited motivational or innovative approaches discussed.

The implications for nursing practice include; undertaking a wider investigation of the perceptions of clinical leadership and approaches to leadership development for senior nurses and care home managers in other aged care residential facilities. Initiating a training program to support the development, understanding and application of clinical 
Citation: Stanley D, Latimer K, Atkinson J (2014) Perceptions of Clinical Leadership in an Aged Care Residential Facility in Perth, Western Australia. Health Care Current Reviews 2: 122. doi: 10.4172/2375-4273.1000122

leadership with an emphasis on the development of skills related to a range of issues such as; understanding the difference between leadership and management, understanding clinical leadership, managing change, clinical decision making, team working, networking and delegation, conflict management, motivation, the leader's role in quality management and issues of empowerment. Further suggestions are to develop strategies for dealing with staff whose English language skills were poor or need to be developed further. It was also noted that participants in the study were generally of advancing age and while not a focus of the study it is suggested that this is in urgent need of attention.

\section{Conclusion}

This study has offered a set of data from questionnaires and interviews with senior nursing staff and care home managers at a residential care facility. The study sought to investigate the perceptions of clinical leadership and approaches to leadership development. Participants were able to express their understanding of clinical leadership and describe the characteristics or attributes they saw as vital for a clinical leader. Also offered, was data about how leadership skills were obtained and insights into the difference between leadership and management. Participants were also able to identify the issues that may hinder or stifle clinical leadership development in the aged care environment and recommendations and suggestions were made that have implications for nursing practice.

\section{References}

1. Australian Institute of Health and Welfare (2007) Older Australia at a glance. (4thedn).

2. Australian Institute of Health and Welfare (2006) Chronic disease and associated risk factors. AlHW, Canberra.

3. Pearson A, Nay R, Koch S, Ward C, Andrews, et al. (2001) Australian aged care nursing: A critical review of education, training, recruitment, and retention in residential and community settings. National review of nursing education, science and training. National Review of Nursing Education. LaTrobe University, Melbourne.

4. Pearson A, Nay R, Koch S, Ward C, Andrews C, et al. (2002) Australian aged care nursing: A critical review of education, training, recruitment and retention in residential and community settings, National Review of Nursing Education 2002, Department of Education, Science and Training and Department of Health \& Ageing

5. Stack S (2003) Beyond performance indicators: A case study in aged care. Australian Bulletin of Labour 29: 143-161.

6. Moyle W, Skinner J, Rowe G, Gork C (2003) Views of job satisfaction and dissatisfaction in Australian long term care. J Clin Nurs 12: 168-176.

7. Eley R, Hegney D, Buikstra E, Fallon T, Plank A, et al. (2007) Aged care nursing in Queensland - the nurses' view. J Clin Nurs 16: 860-872.

8. Duffield C, Roche M, O'Brian-Pallas L, et al. (2007) Glueing it all together Nurses their work environment and patient safety. Centre for Health Services Management, University of Technology, Sydney, Australia.

9. Australian Government (2011) Department of Health and Ageing

10. Stanley D (2006) Part 1. In Command of Care: Clinical Nurse Leadership Explored. Journal of Nurse Research 11: 20-39.

11. Stanley D (2006) Part 2. In Command of Care: Towards the theory of Congruent Leadership. Journal of Nurse Research 11: 134-144.

12. Stanley D (2011) Clinical Leadership: Innovation into Action. Palgrave Macmillan, South Melbourne.
13. Stanley D, Cuthbertson J, Latimer K (2012) Perceptions of clinical leadership in the St. John Ambulance Service in WA. Response 39: 31-37.

14. Department of Health (WA) (2004) Strategic intent 2005-2010.

15. Department of Health and Aging (2008) Office of Aged Care Quality and Compliance. Report to the Minister for Ageing on residential care and people with psychogeriatric disorders.

16. Department of Health and Aging (2008) Better Practice - Visionary leadership in aged care.

17. SØrensen EE, Delmar C, Pedersen BD (2011) Leading nurses in dire straits: head nurses' navigation between nursing and leadership roles. J Nurs Manag 19: $421-430$

18. Swanwick T, McKimm J (2011) ABC of Clinical Leadership. BMJ Books, WilleyBlackwell.

19. Stanton E, Lemer C, Mountford J (2010) Clinical Leadership: Bridging the divide. Quay Books, London, UK

20. Cook M (2001) The Renaissance of clinical leadership. International Council of Nursing International Nursing Review 48: 38-46.

21. Firth K (2002) Ward Leadership: Balancing the Clinical and Managerial Roles. Prof Nurse 17: 486-489.

22. Stanley D (2008) Congruent Leadership: Values in Action. J Nurs Manag 16 519-524.

23. Malcolm L, Wright L, Barnett P, Hendry C (2003) Building a successful partnership between management and clinical leadership: Experience from New Zealand. BMJ 326: 653-654.

24. Stanley D (2014) Clinical Leadership Chracteristics Confirmed. J Res Nurs 19 118-128.

25. Higgins I, Madjar I, Walton JA (2004) Chronic pain in elderly nursing home residents: the need for nursing leadership. J Nurs Manag 12: 167-173.

26. Vogelsmeier A, Scott-Cawiezell J (2011) Achieving quality improvement in the nursing home: Influence of nursing leadership on communication and teamwork. J Nurs Care Qual 26: 236-242.

27. Jeong SY, Keating D (2004) Innovative leadership and management in a nursing home. J Nurs Manag 12: 445-451.

28. Venturato L, Drew L (2010) Beyond 'doing': Supporting clinical leadership and nursing practice in aged care through innovative models of care. Contemp Nurse 35: 157-170.

29. Jeon Y-H, Meralyn T, Chenoweth $L$ (2010) Leadership and Management in the aged care sector: A narrative synthesis. Australas J Ageing 29: 54-60.

30. Jirojwong S, Johnson M, Welch A (2011) Research methods in nursing and midwifery. Oxford University Press, Oxford, UK.

31. National Health and Medical Research Council (2007) Australian Code for the Responsible Conduct of Research. Australian Government, National Health and Medical Research Council and the Australian Research Council and Universities Australia.

32. Richards L (1999) Using NVivo in Qualitative Research. Sage, London, UK.

33. Smith A, Flowers P, Larkin M (2009) Interpretative phenomenologicalanalysis. Theory, method and research. Sage, London, UK.

34. Creswell JW (2012) Educational research: Planning, conducting, and evaluating quantitative and qualitative research. (4thedn), Pearson, Boston, USA.

35. Boudah DJ (2011) Conducting educational research. Sage, London, UK

36. Cook M (2001) The Attributes of effective clinical nurse leaders. Nursing Standard 15: 33-36.

37. Stanley D (2006) Recognising and Defining Clinical Nurse Leaders. Br J Nurs 15: 108-111. 